\title{
CRISIS DE LA UNIVERSIDAD
}

\section{DIANÓSTICO CULTURAL Y PROPUESTAS DESDE ALASDAIR MACINTYRE}

\author{
CRISIS OF THE UNIVERSITY
}

cultural diagnostic and proposals from Alasadair MacIntyre

CRISE DA UNIVERSIDADE

diagnóstico cultural e propostas a partir de Alasdair MacIntyre

\author{
Javier de la Torre \\ (Universidad Pontificia Comillas) \\ jtorre@comillas.edu
}

Recibido: $28 / 12 / 2019$

Aprobado: 06/01/2020

\begin{abstract}
RESUMEN
El artículo ofrece una reflexión constructiva, desde el pensamiento de Alasdair MacIntyre, sobre los posibles caminos de salida a la crisis de la Universidad. Para ello plantea la necesidad de formar en la Universidad en la complejidad, el encuentro cultural, en una interioridad y singularidad del sujeto, en una asunción de los riesgos en este cambio de época, en la integración del fracaso junto a los logros, en la importancia de la integración y de las visiones globales, etc. Además, se describen las soluciones más específicamente universitarias que plantea MacIntyre como son la recuperación de la pasión por la investigación dentro de una historia, la importancia de los auténticos maestros y de los grandes libros, la importancia de los bienes internos de cada profesión, la vocación y la unidad de la vida.
\end{abstract}

Palabras clave: Universidad, MacIntyre, maestros, investigación, vocación.

\begin{abstract}
The article offers a constructive reflection, from the perspective of Alasdair MacIntyre, about the crisis of the University. For this, it describes the need to train in the University in the complexity, the cultural encounter, in an interiority and singularity of the subject, in an assumption of the risks in this time of change, in the integration of failure with the achievements, in the importance of integration and global visions, etc. In addition, the more specifically university solutions proposed by MacIntyre are described, such as the recovery of the passion for research within a history, the importance of authentic teachers and great books, the importance of the internal assets of each profession, the vocation and the unity of life.
\end{abstract}

Keywords: University, MacIntyre, teachers, research, vocation. 


\section{RESUMO}

O artigo oferece uma reflexão construtiva, a partir do pensamento de Alasdair MacIntyre, sobre as possíveis saídas da crise da Universidade. Para isso, suscita a necessidade de treinar na Universidade a complexidade, o encontro cultural, a interioridade e a singularidade do sujeito, na assunção dos riscos dessa mudança de tempo, na integração do fracasso com as conquistas, na importância da integração e visões globais, etc. Além disso, são descritas as soluções universitárias mais especificamente propostas por MacIntyre, como a recuperação da paixão pela pesquisa em uma história, a importância de professores autênticos e ótimos livros, a importância do bem interno de cada profissão, a vocação e a unidade da vida.

Palavras chave: Universidade, MacIntyre, professores, pesquisa, vocação.

\section{Introducción}

Este artículo pretende una reflexión desde la perspectiva macinteriana sobre la institución universitaria hoy, ofreciendo pistas positivas de salida a la crisis actual. Se desarrolla la reflexión con la metodología macinteriana de situar el problema en su contexto social y cultural y planteando los temas en diálogo con los autores más relevantes. Se incide, en un primer lugar, en los desafíos que el marco cultural y laboral actual lanzan a la Universidad y, en un segundo lugar, se presentan en cinco puntos las claves más esenciales para reformar la Universidad desde dentro.

\section{La universidad en nuestro contexto cultural y laboral}

La primera dimensión de la Universidad es educar para el mundo actual, para el mundo del siglo XXI. Se educa para salir al mundo actual y para dar respuestas al presente. Lo primero que debe ofrecer la Universidad es una visión, un faro, una brújula que ayude a situarnos y orientarnos en nuestro mundo actual y nuestro mundo laboral.

\subsection{Educar para la complejidad. Edgar Morin (1921). Evitar los simplismos}

Todos poseemos ante el mundo sólo conocimientos ambiguos y desordenados. La complejidad se caracteriza por tener muchas partes que forman un todo indisociable y difícil de conocer. Esta complejidad nos inquieta, confunde, desorienta y hace caer en la incertidumbre. La tarea de la Universidad no ha de ser ni ofrecer recetas simples a problemas complejos ni quedar paralizados ante un mundo complejo. La Universidad es una invitación a la indagación, a la investigación, al coraje por saber. Pero hoy, por esta complejidad, cualquier estudio de cualquier aspecto de la experiencia humana ha de ser multifacético (Morin, 2009, 2010). La propia globalización en que vivimos es una estructura compleja, un proceso complejo, una gran organización difícil de comprender.

Esto implica educar más allá de visiones unilaterales y simples. Una visión ortodoxa freudiana está tan trasnochada como el conductismo de Skinner. Una mirada política marxista y leninista es tan limitada como la visión de Adam Smith. En nuestras clases hay que dejar las "guerras de nuestros antepasados", el "mundo bipolar" y ofrecer los debates complejos que se dan hoy en día. Una cuestión esencial que muestra claramente el pensamiento de MacIntyre es la necesidad de enseñar a los alumnos a reconocer lo "provisorio, frágil y limitado" de muchas de nuestras comprensiones, el arte de no saber, a huir de simplismos, que somos herederos de diversas y, a veces, incompatibles tradiciones y a enseñar a captar los problemas interdisciplinarmente, a comprender la complejidad (de complexus, lo que está tejido junto) (Morin, 2011: 51). El ser humano, por ejemplo, no es sólo física (partículas elementales), química (interacción de elementos y compuestos), biología (organismo multiceluar), historia (fruto de largas transformaciones sociales), economía (maximizar beneficios), psicología, 
sociología, literatura, arte. La unidad del ser humano tiene las huellas de todo y no podemos cercenarlo con miradas simples y enfoques unilaterales en la Universidad (MacIntyre, 2012: 273-274).

\subsection{Educar para el diálogo y el encuentro cultural. Anthony Giddens (1938)}

La globalización conforma un mundo de transformaciones que afecta a casi todo lo que hacemos. Todos sentimos sus efectos: "la globalización tiene algo que ver con la tesis de que todos vivimos ahora en un mismo mundo" (Giddens, 2003: 20). La globalización no solo afecta a los grandes sistemas (financiero, comunicaciones, etc.), a lo remoto y alejado del sujeto, sino que es también un fenómeno que influye en los aspectos más íntimos de la persona. La globalización ha penetrado en nuestra forma de sentir y vivir. "La globalización hoy no es accesoria en nuestras vidas. Es un giro en las propias circunstancias de nuestra vida. Es la manera que vivimos ahora" (Giddens, 2003: 31). Hay una revolución mundial sobre cómo nos concebimos a nosotros mismos y también cómo formamos lazos y relaciones con los demás (móvil, viajes). Los cambios culturales llegan hasta la vida personal y emocional y van mucho más allá de las fronteras de cualquier país (Giddens, 2001). Con la globalización, el dinero, las tecnologías, las mercancías, las informaciones y las intoxicaciones "traspasan" las fronteras, como si éstas no existieran, gracias a los medios de comunicación y transportes modernos (informática, satélites, aviones supersónicos).

Por este motivo, las tecnologías han reforzado las interdependencias entre comunidades locales, nacionales e internacionales como no se había visto en ninguna época. Por eso Beck llega a la conclusión de que la globalización significa también acercamiento y mutuo encuentro de las culturas locales. El desafío por lo tanto es si el acercamiento a otras culturas nos lleva al encuentro, la acogida y la comprensión de lo diferente, si educamos en la Universidad para acoger lo distinto. Como ya dijo Benedicto XVI en Caritas in veritate $n^{\circ}$ 16: "A medida que la sociedad se hace cada vez más globalizada, nos hace a todos vecinos; pero no nos hace hermanos". La interdependencia, por lo tanto, sólo llevara a un encuentro a través de un auténtico diálogo, a través del aprendizaje del arte del diálogo profundo y el encuentro, del arte de abrirse a lo nuevo, del arte de aprender a poder no tener la razón. Este diálogo riguroso y en profundidad entre tradiciones y culturas, que tan bien ha desarrollado MacIntyre (MacIntyre, 1992; Torre, 2001) debe hacerse en la Universidad para que no sea mero turismo accidental y superficial y no caer en nuevas formas de explotación. Dialogar con la cultura diferente no es asunto fácil y lleva tiempo. Eso nos hace universales y universitarios.

\subsection{Educar la interioridad para un mundo en cambio. Zygmunt Bauman (1925, 2017). Educar sujetos con profundidad}

Vivimos hoy en sociedades en cambio, en sociedades poco sólidas (que ya no están basadas en la seguridad, los contenidos y ciertos valores), en sociedades líquidas conformadas por la movilidad, la incertidumbre y la relatividad de valores (Bauman, 1999, 2007, 2013). En estas sociedades la búsqueda de la identidad es responsabilidad vital del sujeto y de las comunidades que participa. En la modernidad líquida un valor importante es la necesidad de hacerse con una identidad flexible y versátil que haga frente a las distintas mutaciones que el sujeto ha de enfrentar a lo largo de su vida. El individuo tiene que integrarse en una sociedad cada vez más global, sin identidad fija, maleable, voluble. La identidad se tiene que inventar, crear, moldear. El cambio forma parte de nuestra vida. Todos somos viajeros y nómadas. La Universidad del siglo XXI tiene que llevar a construir sujetos de "interioridad" y "raíces" en un mundo en cambio, donde todos somos nómadas. Siempre en la historia cuando los horizontes culturales y sociales cambian, los individuos encuentran en sí mismos los criterios para actuar y orientarse. "No andes vagando fuera. Vuelve en ti. La verdad habita en el hombre interior" ya decía San Agustín.

La Universidad debe buscar formar gente sólida en un nuevo sentido. No es la solidez estoica, del perfeccionismo, del voluntarismo, de los héroes, de las personas invulnerables. La Universidad debe formar gente sólida en el sentido contrario a volátil e incapaz de ir más allá de los propios deseos. Por 
eso es tan fundamental ayudar a leer lo que nos pasa por dentro, a ser personas capaces de introspección, de autoexamen, de "sentir internamente". Cuando los soportes externos se debilitan, hay que fortalecer y cultivar la interioridad. La Universidad tiene la tarea de construir sujetos con hondura, con profundidad, con capacidad de pensar y sentir internamente. Sin duda, una de las aportaciones del pensamiento de MacIntyre es ayudar a reconocerse como miembros de una historia y una tradición, como sujetos enraizados. La Universidad no sólo debe dar alas para volar en un mundo en cambio, sino también ayudar a los alumnos a reconocer sus raíces, su punto de partida de una familia tradicional o liberal, venidos de una escuela elitista o popular, provenientes de una ciudad cosmopolita o un pueblo afectado por la crisis. La Universidad es un momento privilegiado para reconocer lo que hemos heredado, la tierra desde donde partimos y pensamos. La Universidad es un momento oportuno para el ser humano para hacer una síntesis personal entre lo heredado y el porvenir, entre lo recibido y lo que se desea crear. Es importante descubrir esas raíces heredadas para poder avanzar y formarse desde la realidad, esas creencias que nos conforman, en el sentido de Ortega, para poder crecer.

Por eso, como afirma Michael Henry, en su provocativo capítulo sobre "La destrucción de la Universidad", dentro de su obra La barbarie (1996), una de las tareas más importantes de la Universidad es construir sujetos personales, cultivar lo propio y singular de cada uno, la autorealización personal, lo individual, con esfuerzo y trabajo, la esencia de la humanidad en cada uno frente a las tendencias de la masificación, el igualitarismo y la tecnologización. La Universidad tiene que ayudarnos a trabajar, cultivar y ejercitar nuestros dones y capacidades.

\subsection{Educar para una sociedad en riesgo. Ulrich Beck $(1944,2015)$}

La sociedad del riesgo se caracteriza porque los riesgos sociales, políticos, económicos e industriales tienden cada vez más a escapar a las instituciones de control y protección social. El problema de estos riesgos es que causan daños sistemáticos a menudo irreversibles, crean una mayor desigualdad social por un diferente reparto de los riesgos, un vacío político e institucional que provoca un desencantamiento de las fuentes que daban significado colectivo a los ciudadanos y un aumento del proceso de individualización. La nueva sociedad es fuente de incertidumbre, inseguridad y riesgos. El medio y hasta la especie humana están en peligro. Los medios de comunicación tienen un papel muy importante en la representación de los riesgos pues presentan las noticias de las catástrofes ecológicas, las crisis financieras, el terrorismo, las guerras preventivas. Pero el riesgo no solo afecta al plano personal, sino que también afecta a las instituciones. Las grandes empresas tienen el poder de crear gran número de productos, puestos de trabajo y acumular grandes cantidades de capital, pero también de suprimir muchos puestos de trabajo y trasladar la producción a países con sueldos más bajos y con más bajos impuestos (Beck, 2001: 16).

La Universidad tiene hoy la tarea de formar para afrontar positivamente los riesgos. Los riesgos tienen una dimensión positiva que ayuda a madurar. Es importante ayudar a valorar y calcular riesgos, a ser prudente y equilibrado pues éstos son parte de la vida, del emprender, de una investigación, del amor, del juego, de la innovación, del aprendizaje, etc. La Universidad debe huir de educar en la seguridad, en la tranquilidad, en guetos y enseñar a navegar con coraje e inteligencia en los oleajes de la vida siempre llenos de dificultades, imprevistos, nuevos problemas, riesgos. La mirada histórica que ofrece MacIntyre nos ayuda siempre a comprender la importancia de las crisis personales, sociales, de la tradición y de la cultura y cómo en estos contextos de cambio es donde es importante la formación de personas y comunidades que ayuden a explorar nuevos caminos, reelaborar con imaginación y creatividad, reconstruir de diverso modo, aprender de los otros, innovar el lenguaje para preservar la continuidad (Torre, 2001: 165-178). La Universidad debería formar en épocas de cambio como la que vivimos personas que ayuden a ampliar y renovar la mirada de los problemas. 


\subsection{Educar para trabajar en un nuevo mundo laboral flexible y desigual. Gilles Lipovetsky (1944)}

La Universidad debe preparar para el trabajo, pero también para transformar los nuevos entornos labores hiper-competitivos preocupados obsesivamente por generar beneficios. La Universidad debe formar críticamente ante el fanatismo del trabajo, la adhesión emocional a la empresa, la adicción a trabajar y estar siempre conectados, a hacer del trabajo una religión, un hogar de identidad en un mundo sin hogar. También debe formar ante el distanciamiento que lo considera mero medio de subsistencia, una mera ocupación para sobrevivir, un funcionariado de la sociedad. La Universidad debe enseñar la importancia del trabajo y del ocio, de laborar y descansar creativamente.

La Universidad debe hacer consciente que el valor del trabajo se reduce para muchos al dinero que proporciona. El trabajo se ha mercantilizado y está generando una profunda desigualdad (Stigliz, 2012; Piketty, 2015) entre los que trabajan y no, entre personas con contratos fijos y temporales, entre trabajos degradantes (cadenas montaje, basureros, criadas, limpiadoras de hotel, etc.) y esclavizantes y los trabajos de una minoría de profesionales liberales tienen todavía el monopolio de ciertas áreas adquiriendo grandes cantidades de dinero para consumir más y buscarse normalmente a sí mismos. Sigue habiendo dos grandes clases de trabajo: el profesional y el de la subclase de los marginados (Galbraith, 1992). Los salarios son de dos velocidades, se erosionan los sistemas de protección social, se multiplican las horas extras sin pagarse. La Universidad debe formar en la realidad del mundo laboral al que van para asumir lo mejor de él y transformar esos elementos de desigualdad e insolidaridad que dominan muchas empresas e instituciones. La Universidad debe ayudar a superar desigualdades injustas, el clasismo, los privilegios infundados, etc.

Finalmente, la Universidad debe formar para saber poner límites a un mundo en progresiva desregulación y flexibilización del mercado de trabajo que les va a afectar en forma de contratos parciales, basura, en prácticas, pasantías gratuitas, impago de horas extra, abaratamiento de los despidos (Lipovetsky, 2005, 2016). Esta hiperactividad está debilitando los vínculos comunitarios, las relaciones familiares y sociales y la comunicación pues el trabajo hace que no se tenga tiempo para estar con los hijos, la pareja, los padres mayores, salir con los amigos. La Universidad debe educar para saber que el trabajo puede devorar la vida, que hay hiperactividades que destruyen, competitividades que se convierten en esclavitud de las demandas del mercado y vínculos que son más importantes que determinadas conquistas laborales. La Universidad debe dar esa sabiduría para entrar en el mundo del trabajo no para ajustarse perfectamente a una maquinaria sin pensamiento y creatividad, ni para desajustarse en críticas destructivas que no hacen avanzar. El pensamiento de MacIntyre ofrece un modelo para no ser ni apocalípticos, ni integrados en un mundo laboral que tiene el peligro de convertir los medios económicos, burocráticos, técnicos y jurídicos en fines y no en medios (MacIntyre, 1987). La Universidad debería ayudar a plantear críticamente esta tensión entre medios y fines y los peligros de la absolutización en el mundo laboral de las nuevas tecnologías, de la eficiencia burocrática, de la maximización económica o de una reglamentación detallada siempre a la defensiva (Torre, 2005: 357-385).

\subsection{Educar para el fracaso en un mundo que busca con desmesura el éxito. Victoria Camps (1941)}

El psicólogo y antropólogo Ernest Becker (2003) dice que el individuo actual necesita dos cosas: sentirse parte de algo y sobresalir. Necesita sentirse arropado por algo que lo integre como sentirse un elemento imprescindible. Si la ética calvinista predicaba el ahorro y la austeridad, ahora se predica el lujo, la ostentación, el dinero y el bienestar como prueba de la excelencia. Es la necesidad de sobresalir. Por eso el hombre de éxito debe mostrarlo.

Victoria Camps (1990: 99-100) pone el ejemplo del ejecutivo, pieza prioritaria del funcionamiento social. En sus manos están las claves de la producción del dinero. Es el empleado de una sociedad superburocratizada donde lo más importante es saber ejecutar las ideas más que tener ideas. Son 
hombres hechos a sí mismos, disciplinados, enérgicos, seguros de lo que hacen, decididos, inteligentes y pragmáticos. El ser se hace y se representa a sí mismo, es inasequible al desaliento y sabe mostrarse distendido, simpático y divertido en el ocio. Es la excelencia lograda. El trabajo es ocasión de encumbramiento, de ser el número uno, de éxito y riqueza, de reconocimiento externo. No busca la sobriedad y el ahorro sino la ostentación y el despilfarro. No busca la moderación sino el orgullo y la soberbia.

El problema es que hoy puede llegar en cualquier momento un despido, una fusión, un divorcio, una enfermedad fulminante. La Universidad debe educarnos también para el fracaso, para la disminución, para la mengua, para ser más con menos. La Universidad debe ayudar a desarrollar capacidades, pero también enseñarnos a saber parar, a integrar esos momentos de paro y de ausencia de trabajo, de fragilidad, de vulnerabilidad, de depresión, de desorientación. La Universidad debe trabajar y ayudar a valorar la 'fuerza' de la vulnerabilidad y la resiliencia de los seres humanos. La obra de Alasdair MacIntre, Animales racionales dependientes, nos ofrece un camino para integrar positivamente la limitación, la dependencia y la vulnerabilidad en la vida humana pues forman parte de lo constitutivo del ser humano no sólo en el inicio y el final de la vida sino en toda la vida (MacIntyre, 2001).

\subsection{Educar para la integración. Allan Bloom (1930-1992). Contra la fragmentación}

Bloom clama en varios de sus libros (Bloom, 1989, 1991) contra la fragmentación cognoscitiva y el relativismo moral de occidente y de la universidad fruto del emotivismo moral. El problema central está en la multiversidad (Kerr, 1996): la universidad ha dejado de ser un lugar para aprender las cuestiones permanentes y se ha convertido en un espacio de formación de profesionales especializados, en un lugar de especialistas. Esta orientación es la predominante en los gestores y estudiantes que buscan eficiencia más allá de las metas de la universidad.

La especialización ha desplazado la misión de la universidad y el conflicto entre ideales de vida buena. No se ofrece un modo de vivir, un ideal de vida buena. Por eso no hay un proyecto unitario de estudios, de unidad de estudios o sobre la unidad de la vida. Los planes de estudios a veces son un sumatorio de asignaturas patrimonio de determinados profesores o una colección fortuita de temas a gusto de alumnos, padres o empresas.

Los planes de estudios deben ser algo estructurado inteligentemente que ponga en contacto al alumno con lo mejor dicho, escrito y hecho del presente y del pasado. Por eso, la propuesta de Bloom es la vuelta a los viejos grandes libros, no como arqueología, sino para adquirir una visión intelectual del mundo, una visión moral y estética, libros que ofrecen una relación con la vida, con la educación moral, incitan a la vida decente, refinan el gusto y presentan diferentes explicaciones de la experiencia. Estos libros proporcionan un fondo de experiencias y pensamientos compartidos, ofrecen grandes cuestiones, métodos.

La Universidad, por ello, debe invitar realizar construcciones sistemáticas, órdenes de totalidad, a encontrar el significado de cada parte dentro de una estructura, a integrar, a elaborar un pensamiento de conjunto más allá de los fragmentos (MacIntyre, 2012: 272-273). Hoy nadie pretende tener una cosmovisión única, absoluta, definitiva, cerrada y final, pero es triste que la universidad hoy no proporcione algún "horizonte global". Toda persona necesita proyectarse hacia algún futuro y horizonte y lo que parece cierto es que sin la tensión por construirla y sostenerla no es posible un proyecto humano (González, 2016). La universidad debe dotar de horizontes más amplios que la superficialidad plana que muchas veces ofrece nuestra cultura.

\subsection{Educar para el conflicto y el diálogo. Alasdair MacIntyre (1929)}

Para el filósofo escocés la Universidad debe ser un lugar para afrontar sin miedo el conflicto pues los conflictos ni son meramente políticos, ni accidentales sino son estructurales (MacIntyre, 1992, 2012). 
Ni todo es traducible ni todos pensamos lo mismo. Por eso para MacIntyre la universidad es un ámbito de encuentro para los desencuentros, es un lugar de desacuerdo obligado y participación en el conflicto, de incitación a los estudiantes al conflicto desde una perspectiva ad intra y ad extra. Ad intra como representantes de un punto de vista particular, ayudando a avanzar la investigación desde un punto de vista, avanzando y transformando los acuerdos iniciales, articulando esos acuerdos y ad extra en controversia con otros pareceres rivales, ordenando conflictos, proporcionando medios institucionalizados para su expresión, negociando los modos de desencuentro entre los adversarios, asegurando que las voces rivales no sean suprimidas de forma ilegítima. La Universidad no es una arena neutral sino una arena de conflicto sin dejar de afirmar las áreas de acuerdo sin las cuales el mismo conflicto y desacuerdo son estériles. Por eso una tarea fundamental de la Universidad es enseñar a realizar debates entre modos rivales de justificación racional. Las Universidades deben enseñar cómo conducir los debates para ser justificados teóricamente, deben hacer las preguntas que los políticos y economistas nunca se hacen, ser un ámbito de diálogo entre centro y periferia, ser expresión de voces rivales, apoyar y ordenar los conflictos y mantener medios institucionalizados para su expresión. Sólo reconociendo las diferencias podremos dialogar, transformar las posturas y posibilitar la integración de ciertos elementos.

\subsection{Educar para la responsabilidad social. Ignacio Ellacuría $(1930,1989)$}

Hoy las categorías clave para la Universidad son las de memoria y responsabilidad. Hay que superar la tentación del intelectual mediático (sustituye el aula por la televisión o grandes foros), del científico o sabio aristócrata (laboratorio convertido en bunker para cultivarse aisladamente del mundo) y del funcionario burócrata (sustituye la inquietud investigadora por la gestión burocrática). La Universidad puede ser hoy un puente privilegiado entre capacitación humana y desarrollo sostenible "respondiendo" con responsabilidad al mundo actual y sus desafíos. Hay una relación estrecha entre distribución conocimiento y distribución miseria. No cabe que nuestras universidades sean cómplices con la insostenibilidad del desarrollo y la ingobernabilidad de los pueblos.

La Universidad tiene una "responsabilidad social" con la cultura, la sociedad, el gobierno y sobre todo con los más vulnerables en nuestras clases en función de nuestra misión formativa. La educación es un instrumento para desarrollo de los pueblos y de las personas. Hay una "forma universitaria" de plantear las relaciones entre educación y desarrollo, educación profesional y desarrollo personal. Ignacio Ellacuría afirmaba que la Universidad no trata sólo de hacer análisis de la realidad sino contribuir a la transformación de la realidad (de la naturaleza, del hombre, de la sociedad) mediante un cambio prioritario de las estructuras (Ellacuría, 1999: 65). La universidad no puede entenderse "como algo fuera de la sociedad, como algo inmune a las solicitaciones y presiones de la sociedad", como una isla social pues está en la sociedad y está a su servicio. Esta función social, este fin social, este telos, es el que explicita claramente la propuesta constructiva de MacIntyre.

\section{La propuesta de Alasdair MacIntyre \\ 2.1. Educar en el dinamismo de una investigación, una historia, un arte}

La Universidad debe insertar en una historia dentro de una disciplina-tarea con una tradición pues todos estamos dentro de una o varias historias. Más allá de una educación para el consenso y para la retórica en la argumentación, la alternativa hoy es introducir a los alumnos en el valor de una investigación-indagación de una disciplina, una práctica u oficio. Sin una auténtica investigaciónprofundización no hay modo de avanzar, valorar, aceptar y rechazar argumentos dentro de una materia.

Nuestras disciplinas deben ser consideradas como prácticas investigativas sobre un aspecto del bien del hombre (abogar, emprender, organizar, curar, cuidar, etc.). La finalidad de la investigación es la mejora y excelencia en la consecución. Por eso hay que insertar a los estudiantes en una comunidad de investigación, en el hábito del debate y ayudarles a apasionarse por las cuestiones debatidas en la clase como fundamentales para su existencia social compartida. Lo deseable es que los alumnos se sientan 
partícipes de una búsqueda, una indagación, de una aventura que merece la pena continuar. No podemos limitarnos a la descripción de hechos, a decir quién lo dijo, quién influenció a quién, todas ellas preguntas intemporales. Hay que hacer bajar a los alumnos a la historia, a los contextos. No hay buena psicología sin historia de la psicología, no hay una buena filosofía sin una historia de la filosofía. Se tienen que sentir dentro de una historia de una búsqueda de un bien para la humanidad.

La condición previa es que el alumno ha de aprender a convertirse a sí mismo en un aprendiz de un arte, de una técnica que lleva a la obtención de ciertos productos finales, de ciertos productos excelentes y perfectos, que sirven como fin compartido de ese arte y que se logran sólo cooperativamente con otros. El aprendizaje de un arte supone educar el deseo hacia lo que consideramos lo excelente. Se trata de informar el deseo por el pensamiento, de deliberar sobre lo deseado. Para ello es necesaria la disciplina y la transformación de los deseos iniciales. En el acompañamiento a los doctorandos esto se hace evidente: a algunos hay que ayudarles a ampliar lecturas, a otros a hacer síntesis de tanto leído, a unos a buscar la perspectiva propia, a algunos a ser más pacientes y a otros más críticos, a unos más claros y sistemáticos y a otros menos simplistas. Esto implica un progreso en el alumno y en el investigador hacia lo mejor superando la inmadurez inicial por falta experiencia, falta de relaciones, falta de disciplina de las pasiones o una equivocada educación. Educar el deseo es esencial pues caben deseos sin disciplinar, engaños de razón, premisas falsas, razonamientos incoherentes, defectos, hábitos que no ayudan a progresar. La excelencia no se consigue tanto por la satisfacción del deseo como por la educación del deseo. Ya decía Platón que la educación es aprender a desear lo conveniente.

\subsection{Educar acercando a los grandes textos}

En una cultura de artículos de impacto, la Universidad tiene que poner en contacto con los mejores textos y los acuerdos fundamentales de una disciplina pues no todo tiene la misma importancia. No todas las cosas del presente son susceptibles por igual de ser superadas en el futuro. Algunos elementos pueden ser de tal calidad que resulte difícil prever su abandono. No hay psicoanálisis sin Freud, marxismo sin Marx, Islám sin Corán, liberalismo sin A. Smith, Utilitarismo sin Bentham, bioética sin Beauchamp y Childress. No todo tiene la misma importancia. Hay unos acuerdos, creencias e ideales comunes en ciertas cuestiones y ámbitos que constituyen un fondo latente, una base, para todos los de una disciplina.

En el núcleo de cada asignatura, disciplina u oficio hay siempre una serie de textos canónicos. En Derecho Civil español, Castán o Albadalejo han conformado ha muchas generaciones. En historia de la filosofía, Copleston marcó una época. Muchas actitudes compartidas son informadas por una lectura muy difundida de un cuerpo común de textos, textos que conforman el status canónico de una disciplina particular. La lógica aristotélica, los libros de Euclides, la Sagrada Escritura, la Ética a Nicómaco, la Summa Theologica o El Quijote serían ejemplos de textos con autoridad.

Los textos canónicos son poseedores de un sentido fijo al mismo tiempo que siempre están abiertos a una re-lectura, a una reinterpretación crítica, a realizar algunas añadiduras y tachaduras, a diferentes conjuntos de interrogantes. Qué son las cosas o los conceptos se responden con una cita de un texto canónico o un ejemplo paradigmático. Durante mucho tiempo los textos fundamentales eran enseñados, debatidos y discutidos en la Universidad. Se reforzaba la práctica del debate formal e informal entre los estudiantes sobre un cuerpo de textos común. Estos textos esenciales tienen tanta fuerza que también ayudan a descubrirse uno mismo. Son textos que interpretan al lector. El lector es interpretado de esta forma por los textos, aprende sobre sí mismo, es transformado mediante su lectura. Hay que poner en contacto con las mejores obras de la asignatura, los mejores productos. No puede ser que lo que memoricen sean malos apuntes pasados de unos a otros. Un buen libro clarifica conceptos, definiciones, tiene un dinamismo de aprendizaje, plantea un sistema, da una orientación, abre a un mundo. 


\subsection{Educar siendo maestros}

Hay un olvido de los grandes maestros, de las biografías de grandes personajes de la profesión o asignatura. Faltan modelos a los que mirar. El maestro es el personaje modélico y consultivo por antonomasia, ejemplo de cómo descubrir y encarnar unos criterios y que ofrece al alumno la posibilidad de reconocer los defectos que le apartan de su fin, qué aptitudes hay que cultivar y adquirir para poder actualizar sus potencialidades.

La persona necesita dos cosas: un maestro y la confianza en lo que el maestro declara. Sólo así puede uno transformarse uno mismo en una clase diferente de persona. Los maestros ayudan a identificar los defectos y limitaciones de la persona particular aquí y ahora respecto de la excelencia última, ayudan a identificar las insuficiencias del deseo, gusto, hábito y juicio de la persona. El aprendiz descubre que ha de ser transformado si quiere lograr determinadas obras maestras. El maestro ayuda pues ejemplifica los mejores criterios, ayuda a realizar distinción entre la excelencia última y la que puede el aprendiz en sus concretas circunstancias, ayuda a identificar los defectos y limitaciones, enseña qué virtudes han de ser aprendidas y qué vicios han de ser desterrados, ayuda a saber avanzar desde la propia realidad hacia la obra perfecta y enseña a reinterpretar la disciplina en formas nuevas, cómo unir el pasado y el futuro. Por eso, lo que necesita la Universidad no son profesores y gestores sino sobre todo maestros.

\subsection{Educar en la pasión por el bien interno de la profesión}

La Universidad debe enseñar a realizar bien la práctica profesional. No se trata de hacer prácticas, ni multiplicar actividades frenéticamente y sin rumbo. La práctica es lo que configura artes como la pintura, ciencias como la física y la astronomía, juegos como el ajedrez y el fútbol, actividades productivas como la agricultura o la arquitectura, etc. La práctica es, para MacIntyre, una forma coherente y compleja de actividad humana socialmente establecida para lograr los bienes internos a esa forma de actividad en el curso del intento de alcanzar las normas de excelencia propias.

En la historia de cada profesión surgen y se transmiten esas prácticas que permiten lograr los bienes de cada profesión (curar, juzgar, abogar, etc.). Pero la participación en las prácticas implica acatar las pautas y modelos que en ese momento rigen en ella. Un jugador de ajedrez no puede alcanzar cierta excelencia o ciertos bienes internos a menos que acepte que los más expertos le corrijan y que tome como modelo ajedrecista ciertas partidas y ciertos jugadores. Someter las preferencias y gustos personales a las pautas y modelos comunitarios no significa que haya que aceptar sin discusión todo lo que diga el resto de los participantes, pues sin discusión sobre lo que es ser un buen jugador de ajedrez o pintor o abogado, la tradición no avanza. Pero lo que aportan las prácticas es que los juicios no son subjetivos y no cabe un análisis emotivista. Aunque uno puede conceder más importancia a unas habilidades que a otras, no puede decidir por sí mismo qué se considera una respuesta apropiada. Por eso, el concepto de práctica es un concepto clave moral y políticamente, pues contribuye a evitar la arbitrariedad y a superar un relativismo total.

Lo que tiene que enseñar la Universidad es que las prácticas requieren alguna clase de asentamiento institucional. No pueden ser sostenidas simplemente por la excelencia de esas prácticas. Las instituciones están necesariamente envueltas en recursos, distribución de poder, status y bienes externos que siempre son susceptibles de buen y mal uso. Por ese motivo, la práctica no puede ser sostenida sin una institución y por ello, es siempre vulnerable a la corrupción de los bienes externos. Pero sólo es en ellas donde el individuo encuentra sus bienes, se encuentra a sí mismo (me siento pintor, abogado) y desarrolla las habilidades para adquirir los bienes "internos". 


\subsection{Educar en la búsqueda de una vocación y una unidad de modo de vida}

La Universidad supone ayudar a insertarse en narrativas, en la búsqueda de un bien y reconocerse encajado en narrativas más amplias. Ante tanta fragmentación es esencial educar en la vinculación entre acciones, intenciones y narrativas. Nuestras acciones hemos de referirlas a los deseos, intenciones y fines de la persona. Las intenciones a corto plazo sólo se hacen inteligibles por referencia a algunas intenciones a más largo plazo. Nuestras vidas revisten la forma de un drama. Tienen planteamiento, nudo y desenlace. Porque vivimos narrativamente nuestras vidas y porque entendemos nuestras vidas en términos narrativos, la forma narrativa es la apropiada para entender las acciones (MacIntyre, 1987). La Universidad debe alentar a construir la historia de la propia vida, a ir atisbando y esculpiendo el papel que quiero desempeñar en el Gran Teatro del Mundo, a apasionarse por la propia profesión, por el bien que se entrega a la sociedad. Lo importante es comprender que con determinadas acciones voy construyendo mi historia. Al pintar, escribo mi biografía de pintor. Al abogar, de abogado. Por eso tenemos que ayudar a nuestros alumnos a que aprendan a contar su historia, a construir una narrativa más amplia, a construir su futuro, lo que desean ser.

Eso implica ayudarles a preguntarse qué quieren ser en la vida, qué identidad quieren construir, qué valores desean que unifiquen su vida individual. Pero la unidad de la vida humana es la unidad de un relato de búsqueda siempre abierto. La vida humana puede fallar, como la búsqueda a veces fracasa, se frustra, se abandona o se distrae. Pero esa búsqueda de una meta final sólo se descubre mediante encuentros y enfrentamientos, con las dificultades y facilidades, los bloqueos y las dudas, las tentaciones y distracciones que se dan en la búsqueda de lo que queremos. Por eso, tenemos que ayudar a los alumnos no sólo a alcanzar los bienes internos a las prácticas sino a sostenerlos en mitad de los riesgos, peligros, conflictos, tentaciones de la búsqueda de la excelencia del arte, de su identidad y de la unidad de su vida.

La Universidad debe ayudarles también a comprender que su vocación y su elección se sitúa dentro de contextos más amplios. La historia de nuestras vidas aparece, por lo general, típicamente encajada en las historias más amplias y extensas (familia, ciudad, profesión, etc.). La historia de uno mismo está inserta en la historia del mundo, narración global en la que toda narración tiene su sitio. El fenómeno de encaje pone de relieve otra cuestión fundamental: no existimos aislados. Ningún hombre es una isla. Todos estamos en contacto o encajados con otros. Todos tenemos que integrar nuestras distintas actividades dentro de actividades e historias más globales que le dan sentido. Con los años uno se convierte en matemático, filósofo, empresario, abogado, fiscal, escritor, político porque busca determinados bienes de una forma esencial en su vida. Y encontrando su papel, su modo de vida, encuentran su contribución al bien común, a la comunidad, a la historia como ingenieros, economistas, filósofos, etc.

\section{Conclusión}

La función de la Universidad es labrar actitudes, educar el deseo, estimular la pasión por nuevas cosas y modos de vida que merecen la pena. Los docentes tenemos que ayudar a construir un sujeto arraigado y con capacidad de buscar bienes fundamentales para la sociedad desde la vocación personal. Para construir sujetos tenemos que invitar a la acción más que a conocer determinadas teorías. No basta con hablar de justicia o saber del valor de la justicia sino que es necesario ser justos. Para alcanzar y realizar lo excelente es necesaria la práctica, es fundamental con-formar la conducta y con-solidar la buena voluntad con buenas obras. Se trata de actuar más allá del saber y la buena intención. Para ser excelente no basta querer. Tampoco basta saber. Es necesaria la práctica. Por eso la construcción del sujeto se realiza con maestros, buenos libros, comunidad de investigación y mejorando nuestras prácticas profesionales.

La Universidad tiene que plantear caminos a la cima, búsquedas de excelencia, potencias que humanizan, que elevan. Aunque no siempre podamos vivir en la cima, todos necesitamos un cielo abierto para seguir la luz de las estrellas, una guía para vivir entre las muchas simas de la existencia. 
Las cimas y excelencias nos hablan de progreso-dinamismo en la vida, de no estar parados. Por eso la Universidad también tiene que ofrecer prácticas de mejora que nos ayuden en nuestro camino. No son ideas sino prácticas que constituyen lo que somos. Los seres humanos somos excelentes por nuestra razón pero también deberíamos distinguirnos por nuestro deseo y afecto. La excelencia del corazón nos hace más dignos. La propuesta de MacIntyre de Universidad nos lleva a concentrarnos en la disposición profunda del sujeto, en la calidad de sus sentimientos e imaginaciones, sus modos de sentir más que modos de hacer. Ese sentir universitario implica una mirada serena a la complejidad y al encuentro con lo diferente, una sensibilidad abierta al cambio, de coraje e innovación ante los riesgos, de saber poner límites ante un capitalismo desbocado y excluyente, de ir buscando totalidades de sentido en marcos más amplios más allá de nuestro espacio y tiempo. Esa es gran parte de la belleza de la Universidad, descubrir que el corazón de nuestros estudiantes se ha universalizado, se ha ampliado, se ha solidarizado con su sociedad y su cultura, con la historia y la humanidad.

\section{Bibliografía}

Bauman, Z. (1999). Modernidad líquida. Fondo de Cultura Económica. Buenos Aires.

Bauman, Z. (2007). Tiempos líquidos. Tusquets. Barcelona.

Bauman, Z. (2013). La cultura en el mundo de la modernidad líquida. Fondo de Cultura Económica. Buenos Aires.

Beck, U. (2001). ¿Qué es la Globalización? Falacias del globalismo, respuestas a la globalización. Paidós. Barcelona

Becker, E. (2003). La negación de la muerte. Kairós. Barcelona.

Bloom, A. (1989). El cierre de la mente moderna. Plaza-Janés. Barcelona.

Bloom, A. (1991). Gigantes y Enanos. Interpretaciones sobre la historia sociopolitica de Occidente. Gedisa. Barcelona.

Camps, V. (1990). Virtudes públicas. Espasa-Calpe. Barcelona.

Ellacuría, I. (1999). “Diez años después, ¿es posible una universidad distinta?”, en Ellacuría, I., $I$. Escritos universitarios. UCA editores. San Salvador.

Galbraith, J. K. (1992). La cultura de la satisfacción. Ariel. Barcelona.

Giddens, A. y Hutton, W. (eds.) (2001). En el límite: la vida en el capitalismo global. Tusquets. Barcelona.

Giddens, A. (2003). Un mundo desbocado: Los efectos de la globalización en nuestras vidas. Taurus. Madrid.

González, A. (2016). Bioética: un nuevo paradigma. Tecnos. Madrid.

Henry, M. (1996). La Barbarie. Caparrós. Madrid.

Kerr, C. (1996). The Uses of the University. Harvard University Press. Cambridge, MA.

Lipovetsky, G. (2016). De la ligereza. Anagrama. Barcelona.

Lipovetsky, G. (2006). La era del vacío. Anagrama. Barcelona. 
Lipovetsky, G. (2005). El crepúsculo del deber. Anagrama. Barcelona.

MacIntyre, A. (1987). Tras la virtud. Crítica. Barcelona.

MacIntyre, A. (1992). Tres versiones rivales de la ética. Rialp. Madrid.

MacIntyre, A. (2001). Animales racionales y dependientes. Paidós. Barcelona.

MacIntyre, A. (2012). Dios, filosofía, universidades. Nuevo Inicio. Granada.

Morin, E. (2009). Introducción al pensamiento complejo. Gedisa. Barcelona.

Morin, E. (2010). Pensar la complejidad. Universitat de Valencia. Valencia.

Morin, E. (2011). Los siete saberes necesarios para la educación del futuro. Paidós. Barcelona.

Piketty, T. (2015). La economía de las desigualdades: como implementar una redistribución justa y equitativa de la riqueza. Anagrama, Barcelona.

Stiglitz, J. E. (2012). El precio de la desigualdad. Taurus. Madrid.

Torre, J. de la (2001). El modelo de diálogo intercultural de Alasdair MacIntyre. Dykinson. Madrid.

Torre, J. de la (2005). Alasdair MacIntyre ¿un crítico del liberalismo? Dykinson. Madrid. 